\title{
Optimization of extraction and quantification of Flavonoids from Averrhoa bilimbi fruits using RP-HPLC and its correlation between total flavonoids content against antimicrobial activity
}

\author{
Tan Phat Chau ${ }^{1} \cdot$ Muthusamy Muthusamy ${ }^{2} \cdot$ Arunachalam Chinnathambi $^{3} \cdot$ Tahani Awad Alahmadi $^{4}$. \\ Sowmya Kuppusamy ${ }^{5}$
}

Received: 9 July 2021 / Accepted: 8 August 2021 / Published online: 17 August 2021

(c) King Abdulaziz City for Science and Technology 2021

\begin{abstract}
The present study was conducted to evaluate Averrhoa bilimbi fruits flavonoids extraction and quantification analysis through RP-HPLC and its comparison study on total flavonoids concentration versus antimicrobial activity analysis based on minimum inhibitory concentrations. Optimization of extraction was carried out using three different methods; among all methods the ultrasonic conventional assistant extraction (UCAE) showed an excellent recovery of flavonoids with solid phase elution. UCAE was performed with ethanol using different solvents ratio, the total flavonoid content was quantified through spectrophotometrically $(850 \pm 25 \mathrm{mg} / \mathrm{kg}$ ) and flavonoids (myricetin and luteolin) were quantified by RP-HPLC. Optimized yield of myricetin and luteolin were presented in A. bilimbi fruits $336 \pm 15$ and $231 \pm 18 \mathrm{mg} / \mathrm{kg}$, respectively. Antimicrobial activity examined against $E$. coli, $S$. aureus and $B$. subtilis species using spectroscopically. The extracted sample with known quantity of total flavonoids content (10-200 $\mu \mathrm{g} / \mathrm{mL}$ ) used against $E$. coli, S. aureus and B. subtilis, MIC results shows $55.6 \pm 6,31 \pm 3$ and $28 \pm 2 \mu \mathrm{g} / \mathrm{mL}$ respectively. Higher flavonoid content plays major role on antioxidant activities, which were evaluated and compared with commercial antioxidant butylated hydroxytoluene (BHT) employing superoxide anion scavenging activity and total reducing power $\mathrm{IC}_{50}$ value results shows 100 and $175 \mu \mathrm{g} / \mathrm{mL}$, respectively. The maximum yield of flavonoid content results shows method suitability of flavonoids extraction and quantification.
\end{abstract}

Keywords Anti-oxidant activity $\cdot$ Averrhoa bilimbi fruit $\cdot$ UCAE $\cdot$ RP-HPLC $\cdot$ Flavonoids $\cdot$ Anti-microbial activity

\section{Introduction}

Sowmya Kuppusamy

ksowmyakarthikeyan@gmail.com

1 Institute of Applied Science and Technology, Van Lang University, Ho Chi Minh 700000, Vietnam

2 Department of Agricultural Biotechnology, National Institute of Agricultural Sciences (NAS), RDA, Jeonju 54874, Korea

3 Department of Botany and Microbiology, College of Science, King Saud University, PO Box-2455, Riyadh 11451, Saudi Arabia

4 Department of Pediatrics, College of Medicine and King Khalid University Hospital, King Saud University, Medical City, PO Box-2925, Riyadh 11461, Saudi Arabia

5 PG Department of Environmental Science, Holy Cross College, Tiruchirappalli, Tamil Nadu, India
During COVID 19 period people aware about natural drugs and nutrient balance for immunity, especially antioxidant rich foods. Flavonoids are well-known antioxidant and it is rich in fruits, vegetables and flowers etc. which is also available in wine and tea. Flavonoids are considered as an important natural antioxidants, because the ability of free radical's elimination is high and metal chelation nature of flavonoids inhibits lipid peroxidation activity, its mainly based on phenolic and hydroxyl groups are responsible for antioxidant activity of flavonoids (Karabin et al. 2015). Natural antioxidants (polyphenolics, flavonoids, alkaloids and vitamins etc.) increases human immunity and fights against many pathogenic bacteria and virus. Flavonoids are well-known and scientifically proved antioxidant both in-vitro and invivo methods. It exhibits a wide range of applications, especially anti-inflammation, anti-allergic, anti-cancer, enzyme inhibition and anti-microbial etc. (Adamczak et al. 2020). 
Averrhoa bilimbi fruit (ABF) famous commercial food crop, is a well-known anti -oxidant rich fruit confirmed by both in vitro and in vivo analysis. In ABF several pharmacological applications are investigated scientifically, reported to exhibit pharmacological properties such as anti-diabetic, antimicrobial, antioxidant, anti-carcinogenic, cough, obesity and anti-hypertension etc. (Alsarhan et al. 2012; Goh et al. 1995; Alhassan et al. 2016).

The primary and secondary metabolites of $\mathrm{ABF}$ were reported to have sugars, amino acids, proteins, phenolics, flavonoids, tannins, essential oils and terpenes. ABF rich in vitamin $\mathrm{C}$ and oxalic acid (Hasanuzzaman et al. 2013; Patil et al. 2013). Based on gas chromatographic studies number of volatiles were identified in ABF. The major volatile components is 2,4-dihydroxy-6-((4-methylpentyloxy) methyl) benzaldehyde (Gunawan et al. 2013). Another study, Pino et al. (Pino et al. 2004) reported the presence of 62 volatile compounds especially nonanal, (Z)-3-hexenol, hexadecanoic acid, octane, tricosane, (E)2-decenal, nonanoic acid, (Z)-9-pentacosene, 2-furfural, and (Z)-9-tricosene. The major contribution is aliphatic acid such as palmitic acid, furaldehyde and octa-decenoic acids.

Commercially some synthetic antioxidants that are used as drugs, reported to have some side effects but natural antioxidants like flavonoids are reported to be safe and has no side effects and exhibited various pharmacology applications (Alhassan et al. 2016). Based on the purity of the flavonoid, its application showed better results. The method of extraction of flavonoids plays vital role so as to get maximum yield. Optimization of the methods for the natural product extraction and quantification may reduce the cost.

The major objective of the present study to determine and optimize the extraction and quantification two flavonoids (myricetin and leuteolin) in Averrhoa bilimbi fruit sample using RP-HPLC. Further application of these total flavonoids in exhibiting its antioxidant and antimicrobial capability was analyzed.

\section{Materials and methods}

\section{Sample collection and preparation}

A. bilimbi fruits were purchased from local market and washed with water and cut into small pieces. The samples were lyophilized (freeze drying at $-50{ }^{\circ} \mathrm{C}$ and dried for $48 \mathrm{~h}$ using a vacuum freeze dryer (Christ alpha $1-2 / L D$ plus, Germany) produced maximum yield of $9.5 \%$ of dry extract. Samples were stored in air tight container in refrigerator- $20{ }^{\circ} \mathrm{C}$ until further use (Gülçin et al. 2010).

\section{Conventional-assisted extraction (CAE)}

Stored fruit sample $(1.0 \mathrm{~g})$ were extracted with $50 \mathrm{~mL}$ of $80 \%$ ethanol. Followed $5 \mathrm{M}$ of $\mathrm{HCl}$ was added and refluxed 60-120 min @ $90{ }^{\circ} \mathrm{C}$. The extraction time and solvent ration optimized with various levels. Extracted material kept for cooling at room temperature, and then sample was filtered through Whatman No.1 filter paper. The filtrate concentrated under vacuum (IKA) dryer at $80 \pm 3{ }^{\circ} \mathrm{C}$, extract reconstituted with methanol and filtrate $(0.45 \mu \mathrm{m})$ Axiva nylon syringe filter used to RP-HPLC analysis (Proestos et al. 2005).

\section{Microwave-assisted extraction (MWAE)}

$1.0 \mathrm{~g}$ of freeze-dried fruit sample was extracted with $50 \mathrm{~mL}$ of ethanol $(90 \%$ with $10 \mathrm{~mL} 5 \mathrm{M} \mathrm{HCl})$ in a microwave for 5-20 min. On yield basis, an extraction time and watt optimized for $15 \mathrm{~min}$ at $650 \mathrm{~W}$ microwave energy respectively. The extracts were filtered (Whatman No.1 filter paper) and concentrated under vacuum pressure $\left(80 \pm 3^{\circ} \mathrm{C}\right)$ (Albuquerque et al. 2018).

\section{Ultrasound-assisted extraction (UAE)}

$1.0 \mathrm{~g}$ of freeze-dried fruit sample was taken for sonication with $50 \mathrm{~mL}$ of $90 \%$ ethanol $(10 \mathrm{~mL} 5 \mathrm{M} \mathrm{HCl})$ in an ultrasonic bath at a frequency of $40 \mathrm{kHz}$ (Elma Ultra-sonicator bath, Germany) and temperature maintained at $30 \pm 3{ }^{\circ} \mathrm{C}$ for 30-120 min. based on extraction yield, an extraction time of $60 \mathrm{~min}$ was optimized for maximum yield. The final extracts were filtered and concentrated under vacuum pressure and temperature maintained at $80 \pm 3{ }^{\circ} \mathrm{C}$. The final dried product reconstitutes with methanol and filtrate used for RP-HPLC analysis (Albuquerque et al. 2018).

\section{Ultrasound/conventional-assistant extraction (UCAE)}

$1.0 \mathrm{~g}$ of freeze-dried fruit sample with $50 \mathrm{~mL}$ of $90 \%$ aqueous ethanol was taken, with addition of $10 \mathrm{~mL}$ of $5 \mathrm{M} \mathrm{HCl}$ was added. The mixture was vortexed and mixture was refluxed in a paraffin oil bath at $90^{\circ} \mathrm{C}$ for $60 \mathrm{~min}$. The extract was sonicated at a frequency of $40 \mathrm{kHz}$ in ultra-sonic bath for $10 \mathrm{~min}$. Then the filtrate was centrifuged at $5000 \mathrm{rpm}$ and the supernatant was filtered with $0.45 \mu \mathrm{m}$ membrane syringe filter (Axiva, India) prior to injection.

\section{Solid phase purification}

Silica $\mathrm{C}_{18}$ cartridges was used for purification of targeted compounds (luteolin and myricetin), flavonoid is 
extracted from honey sample method was described by Kaškonienè et al. (Kaškonienė et al. 2009). The solid phase extraction cartridge (SPE) was used Bond Elut octadecyl $\mathrm{C}_{18}(500 \mathrm{mg} / 5 \mathrm{~mL}$, Agilent Technology, USA). Cartridge was set up linked with vacuum compartment and conditioned with methanol 5 and $5 \mathrm{~mL}$ of double distilled water. Sample $5 \mathrm{mg} / \mathrm{mL}$ was loaded onto the cartridge and the elution was collected slowly (drop by drop) adsorption of targeted flavonoids. Further cartridge was washed with $6 \mathrm{~mL}$ of distilled water. The eluted aliquots from cartridge-bound flavonoids fraction was collected using $10 \mathrm{~mL}$ of methanol drop by drop. The eluent was concentrated with rotary evaporator for $5 \mathrm{~min}$ at $65^{\circ} \mathrm{C}$, and reconstituted with known volume of methanol for further analysis.

\section{RP-HPLC analysis}

The HPLC system (Shimadzhu Prominence-i, 2030C Plus, lab solution software) was used for analysis. Reverse phase $\mathrm{C} 18$ was column used for analysis, specification $4.6 * 250 \mathrm{~mm}, 5 \mu \mathrm{m}$ particle size (Shim-pack GIST) was used. Mobile phase Methanol A with $0.1 \% \mathrm{H}_{3} \mathrm{PO}_{4}$ and water $\mathrm{B}$ with $0.1 \% \mathrm{H}_{3} \mathrm{PO}_{4}$ was used. The different mobile phase and methods isocratic and gradients programs were used for HPLC optimization. Finally, gradient program was optimized with good resolution. Optimized gradient program $0.0-35 \min 60-30 \%$ of B, $35-40$ min $60 \%$ of B and $40-45 \mathrm{~min} 60 \%$ of B was used with $1.0 \mathrm{~mL}$ flow rate and $10 \mu \mathrm{L}$ injection volumes. The monitoring wavelength was detected at $370 \mathrm{~nm}$. Data analysis was carried out lab solution software. Sample identification and quantification was done using external standard method.

\section{Total flavonoid content analysis}

An aluminium chloride method was followed with little modification used for determination of total flavonoid content in the natural sample (Rameshkumar et al. 2013). The samples were 50, 100 and $200 \mu \mathrm{L}(1 \mathrm{mg} / \mathrm{mL})$ was added with $600 \mu \mathrm{l}$ of methanol, $40 \mu \mathrm{l}$ of $10 \%$ aluminium chloride, 40 $\mu \mathrm{L}$ of $1 \mathrm{M}$ potassium acetate makeup with $2 \mathrm{~mL}$ of distilled water, and reaction tubes were kept at room temperature for $30 \mathrm{~min}$ in dark. The absorbance was measured at $420 \mathrm{~nm}$ spectrophotometrically. Total flavonoid content was quantified against quercetin equivalent, calibration solution was used the range $0-100 \mu \mathrm{g} / \mathrm{mL}$ in methanol. The amount of total flavonoids was expressed in $\mu \mathrm{g} / \mathrm{mL}$ of fruit extract was quercetin equivalent.

\section{Reducing power capability}

Determination of reducing power was followed by with little modifications (Rameshkumar and Sivasudha 2012) the test mixture contains $2.5 \mathrm{~mL}$ of $0.2 \mathrm{M}$ phosphate buffer $(\mathrm{pH}$ 6.5) with $2.5 \mathrm{~mL}$ of $\mathrm{K} 3 \mathrm{Fe}(\mathrm{CN}) 6(1 \% \mathrm{w} / \mathrm{v})$ of ABFE sample with different concentrations $(50-500 \mu \mathrm{g} / \mathrm{mL})$. The test mixture was incubated at $60^{\circ} \mathrm{C}$ for $15 \mathrm{~min}$, after incubation $2.5 \mathrm{~mL}$ of TCA $(10 \% \mathrm{w} / \mathrm{v})$ added. The blend was centrifuged at $6000 \mathrm{rpm}$ for $8 \mathrm{~min}$. Further $2.0 \mathrm{~mL}$ of supernatant with $2.5 \mathrm{~mL}$ of water and $0.5 \mathrm{~mL}$ of $\mathrm{FeCl}_{3}(0.1 \%$, w/v $)$ were added. The colored solution measured at $700 \mathrm{~nm}$ spectrophotometrically, blank was carried out without samples for control analysis BHT was used as a reference analysis.

\section{Superoxide anion scavenging activity of $A$. Bilimbi fruit extract}

Superoxide anion scavenging activity was carried out using (Yen and Chen 1995) with slight changes. The test solution containing $1 \mathrm{ml}$ of NBT, various concentrations $(50-500 \mu \mathrm{g} /$ $\mathrm{mL})$ of fruit extract, $1 \mathrm{~mL}$ of 60 molar PMS solution $(0.1 \mathrm{M}$ of phosphate buffer with pH 7.4) with 1 mL NADH (Prepared in phosphate buffer), and the solution was incubated $5 \mathrm{~min}$ at $25^{\circ} \mathrm{C}$. The absorbance was carried out at $560 \mathrm{~nm}$.

\section{Antimicrobial sensitivity of $A$. bilimbi fruit extract sample}

The antimicrobial activity was carried out using minimum inhibitory concentration method (Adamczak et al. 2020). Samples were diluted in distilled water with $10 \%$ of dimethyl sulfoxide DMSO because of solubility of flavonoids. 100 $\mu \mathrm{L}$ of fruit sample solution was added to the sterile 96-well plate containing $100 \mu \mathrm{L}$ media (Mueller-Hinton) and 100 $\mu \mathrm{L}$ of bacterial species (E. coli (ATCC25922), S. aureus (CMCC(B) 26003) and B. subtilis (MTTC NO-10110)) used as reference material. The microbial suspension was mixed and absorbance were calculated. Then cultures were incubated $37^{\circ} \mathrm{C}$ for $24 \mathrm{~h}$ and the absorbance was monitored. The without sample incubated microbial plates are used as control sample.

\section{Results and discussion}

Four different extraction methods (CAE, MAE, UAE and UCAE) were followed in this study, the results represented in Fig. 1. Among these methods, UCAE method was optimized for flavonoids extraction. CAE method luteolin and myricetin results show 232 and $328 \mathrm{mg} / \mathrm{kg}$, respectively. Conventional assistant extraction is wieldy using method for extracting secondary metabolites from natural materials. CAE based on reflux, digestion, percolation and infusions. Most of the CAE extraction based on using high volume of organic solvents with high temperatures giving better extraction for highly stable compounds (Proestos et al. 2005).

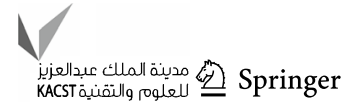


Fig. 1 Bar diagram represented myricetin and luteolin concentration using various extraction methods

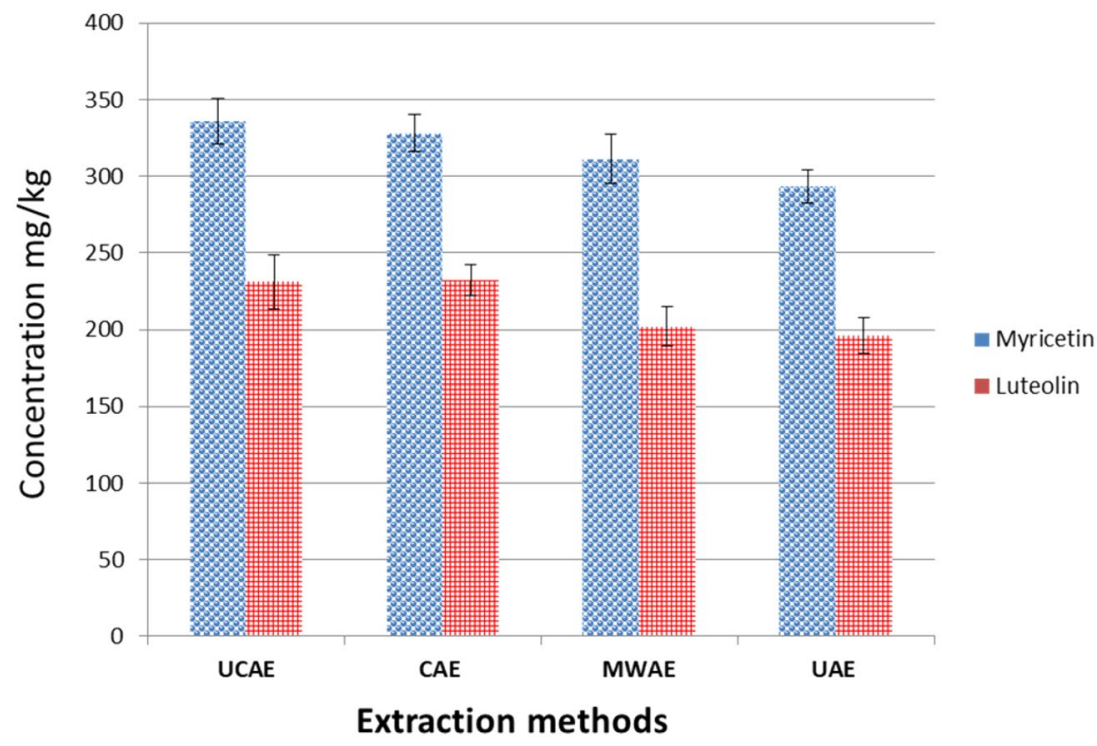

MWAE one of the well-known method flavonoids extraction, Eun Young Jin et al. (2011) reported flavonoid extraction and optimization using MWAE. Maximum yield was obtained (luteolin $202 \mathrm{mg} / \mathrm{kg}$ and myricetin $311 \mathrm{mg} / \mathrm{kg}$ ), respectively, at $3 \mathrm{~min}$ with one min interval three times using $90 \%$ ethanol at $600 \mathrm{w}$. MWAE one of the most widely using method for flavonoid extraction (Xu et al. 2018). Further, enzyme-assisted extraction was used for optimization of luteolin, pigeonpea and apigenin, etc. (Fu et al. 2018).

Luteolin and myricetin yield obtained in 196 and $293 \mathrm{mg} /$ $\mathrm{kg}$, respectively, in UAE. UAE induced damage of the surface tension in cellulose in surface of plant materials, it is happened through soluble nature of material to solvent by osmotic and diffusion mechanism (Prasad et al. 2009; Xie et al. 2014; Zhang et al. 2013). Many flavonoids (rutin, nicotiflorin, catechin, epicatechin gallate, narcissin, rhamnocitrin, myricetin, quercetin and kaempferol) extracted using UAE (Jin et al. 2011).

The combination of ultrasound and CAE gave good recovery among the methods. Due to sonication micro rapture with high temperature rupture the cell wall of plant materials, further flavonoids (luteolin and myricetin) is thermally stable compounds. Among this above methods UCAE was successfully optimized for maximum yield of myricetin and luteolin content (336 and $231 \mathrm{mg} / \mathrm{kg}$ ) in $\mathrm{C}_{18}$ cartridge fraction, when compared with previously reported (luteolin $146.0 \mathrm{mg} / \mathrm{kg}$ and myricetin $202.0 \mathrm{mg} / \mathrm{kg}$ ) by Miean and Mohamed (Miean and Mohamed 2001). Figure 2 shows crude extract of without $\mathrm{C}_{18}$ cartridge chromatogram, it is clearly shows matrix effect on chromatogram. This study UCAE was maximum yield obtained in using $2 \mathrm{~h}$ reflux with $85 \%$ ethanol at $90{ }^{\circ} \mathrm{C}$ Fig. 3. The quantification was done by using RP-HPLC, optimization of liquid chromatography with $0.1 \%$ of ortho phosphoric acid. Retention time (RT) of reference standards (myricetin and luteolin) was 14.43 and 22.99 min, respectively. Figure 4 shows overlay RP-HPLC chromatogram of samples. The quantification was done by external calibration with five points linearity, calibration curve was plotted through serial dilution from higher concentration for myricetin $17.2-275 \mathrm{mg} / \mathrm{L}\left(R^{2}-0.9993\right)$ and for luteolin $21.8-350 \mathrm{mg} / \mathrm{L}\left(R^{2}-0.9995\right)$, respectively (Fig. 5a, b).

The total flavonoids content of fruit sample were expressed quercetin equivalent in $\mathrm{mg}$, total flavonoid content of $A$. bilimbi fruit was quantified $(851 \pm 25 \mathrm{mg} / \mathrm{kg})$ spectrometrically. Based on total flavonoids content further dilution of flavonoids was prepared for anti-oxidant and anti-microbial activities analysis. Other polyphenolics mar present in the extract which used for antioxidant and antimicrobial studies. Previously, Miean and Mohamed (Miean and Mohamed 2001) reported total flavonoid content of A.bilimbi fruit shows $806 \mathrm{mg} / \mathrm{kg}$, when compared with reported value above extraction achieved maximum amount yield of total flavonoids.

Reducing power of $A$. bilimbi fruit extract major tool for in vitro antioxidant activity analysis and it's expressed as strength of bioactive compounds reducing capacities (Jayaprakasha and Patil 2007). The reducing power of fruit extract was compared with commercial antioxidant butylated hydroxyl toluene (BHT). The reducing power of fruit extract shows (Fig. 5) directly proportionally increased were increase concentration of total flavonoid content. The reducing power of total flavonoids concentration $(0-300 \mu \mathrm{g} /$ $\mathrm{mL}$ ) was used the absorbance was measured at $700 \mathrm{~nm}$. The amount of total flavonoids required for reaching absorbance 1.0 at $258 \mu \mathrm{g} / \mathrm{mL}$ for BHT and $275 \mu \mathrm{g} / \mathrm{mL}$ for extract. Gulcin et al. (Gülçin et al. 2010) reported superoxide radical are more risk full to cellular modules; it was precursor of 
Applied Nanoscience (2023) 13:1293-1300

1297

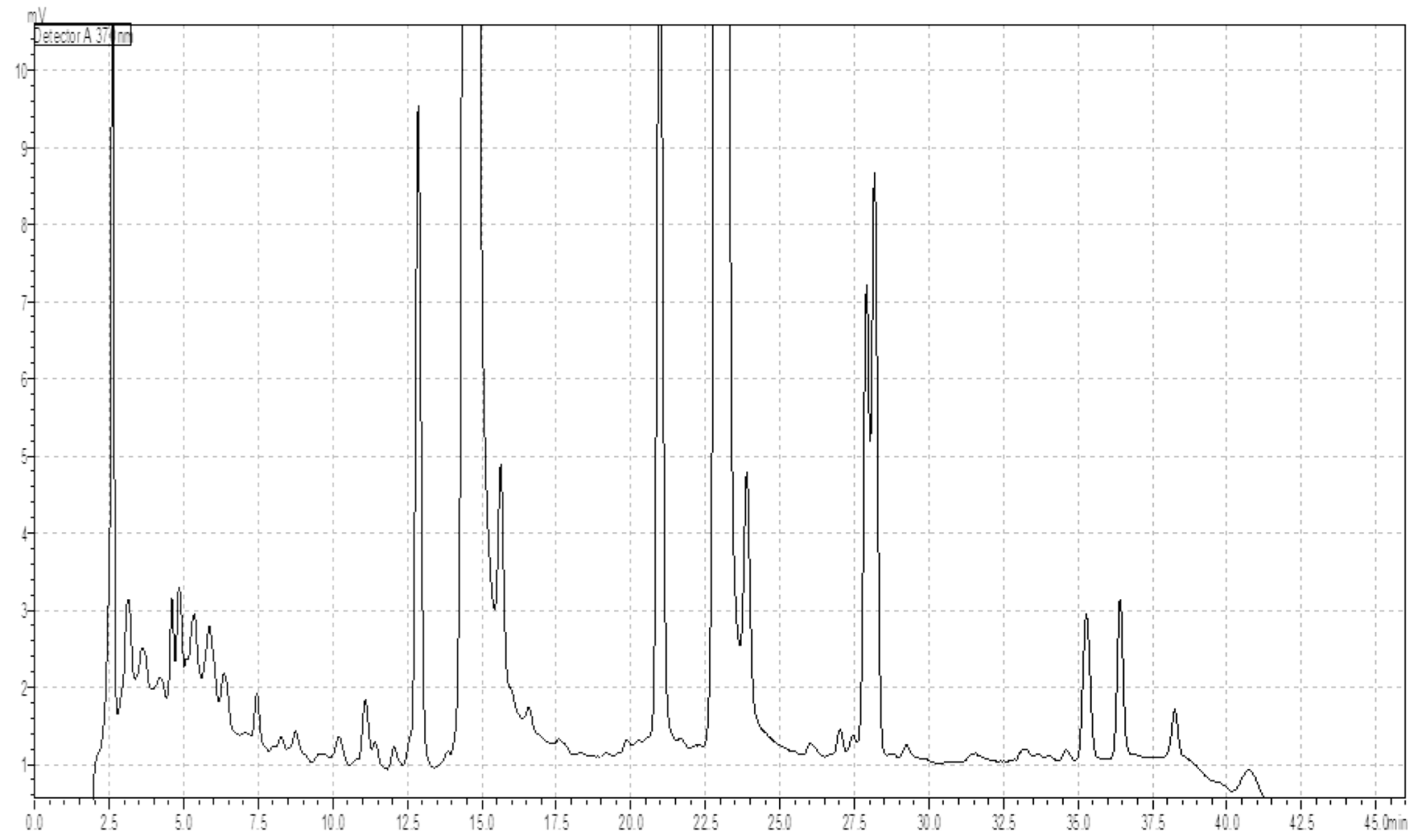

Fig. 2 RP-HPLC chromatogram shows crude extract of A. bilimbi. (UV-VIS detector set at $370 \mathrm{~nm}$, RT-50 min)

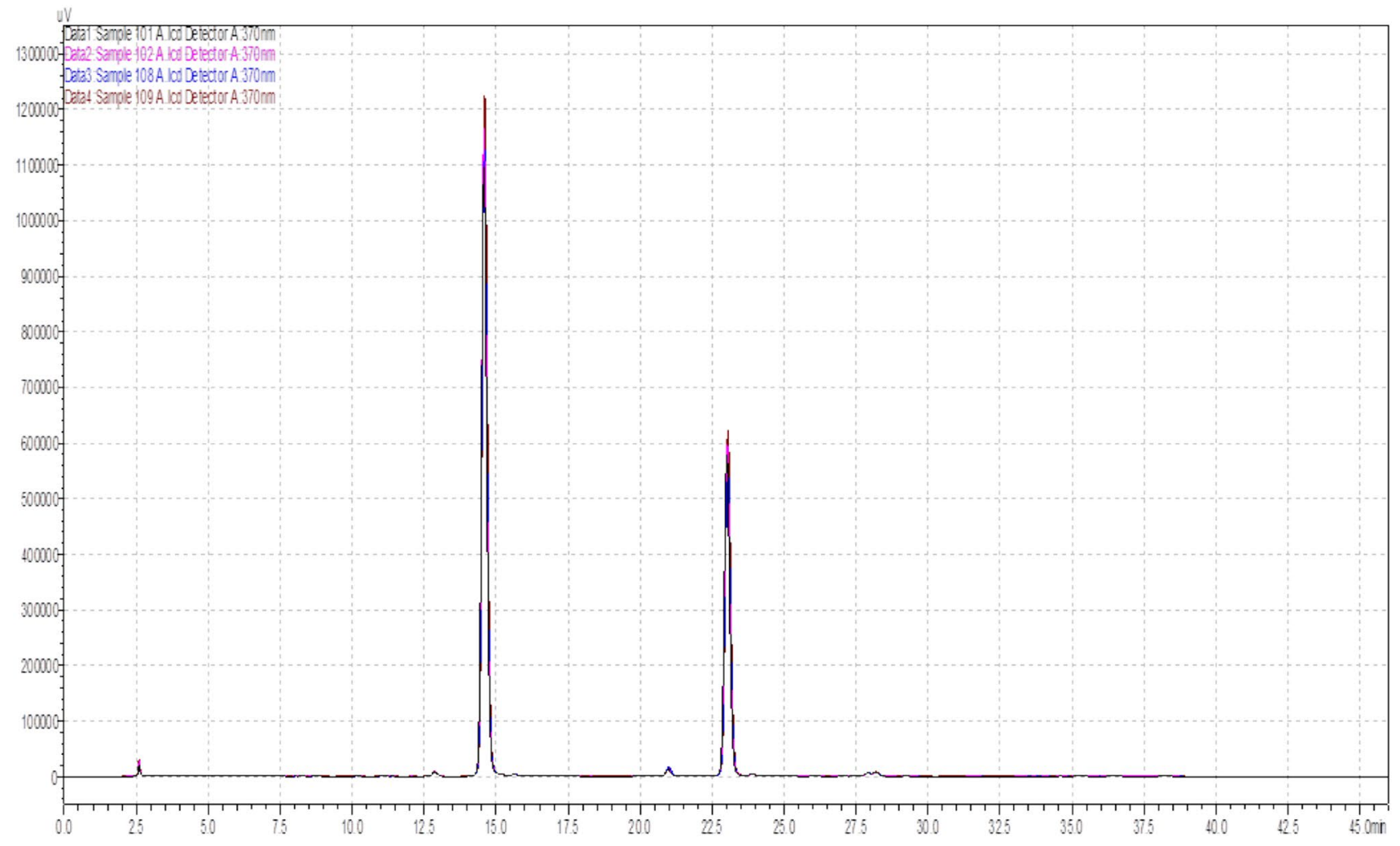

Fig. 3 RP-HPLC chromatogram shows quadruplicate overlay results of UCAE solid phase $\mathrm{C}_{18}$ cartridge fraction of A. bilimbi

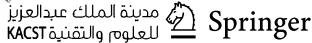



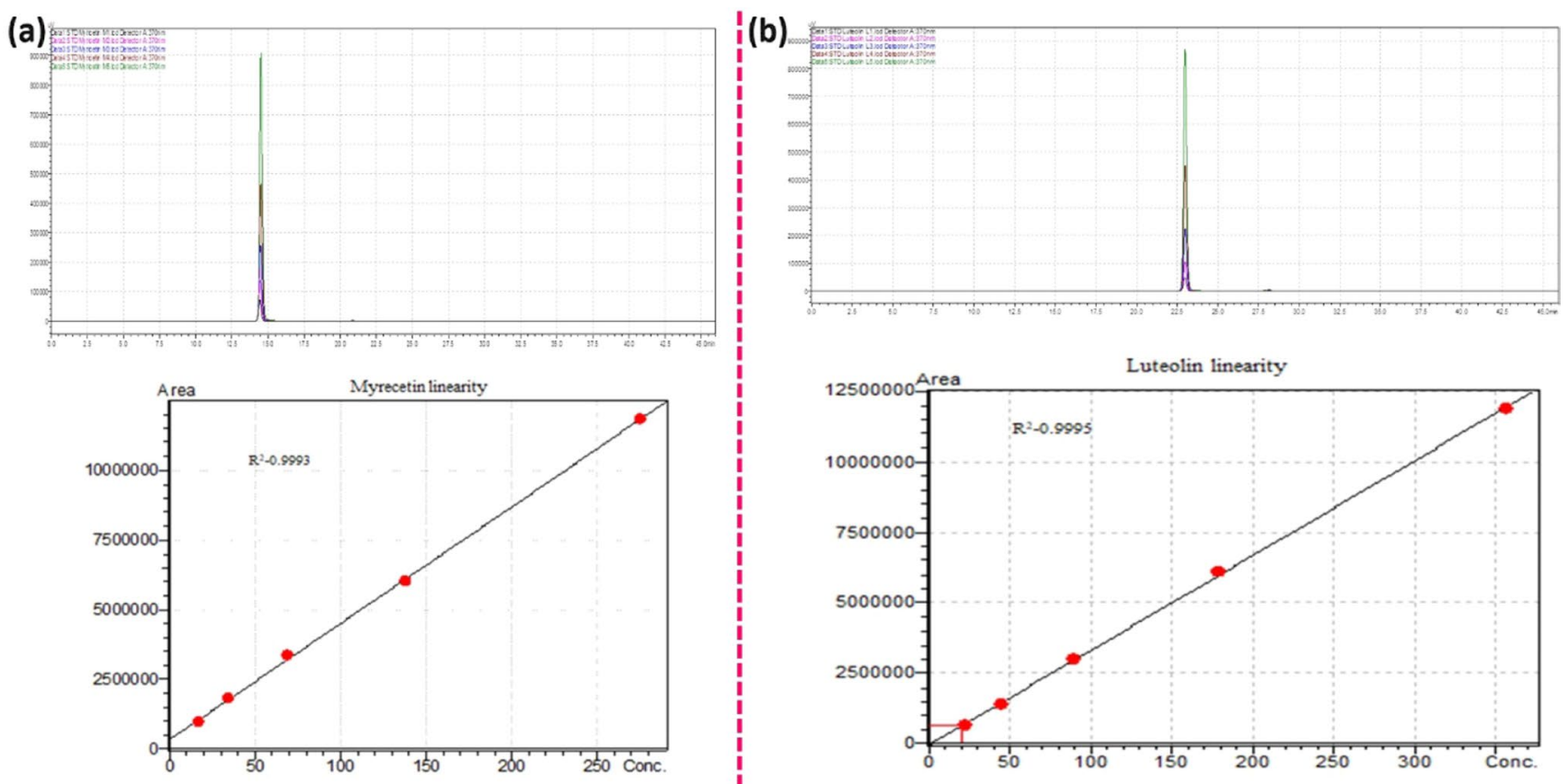

Fig. 4 a RP-HPLC chromatogram shows overlay results of five points linearity of myrecetin. b RP-HPLC chromatogram shows overlay results of five points linearity of luteolin

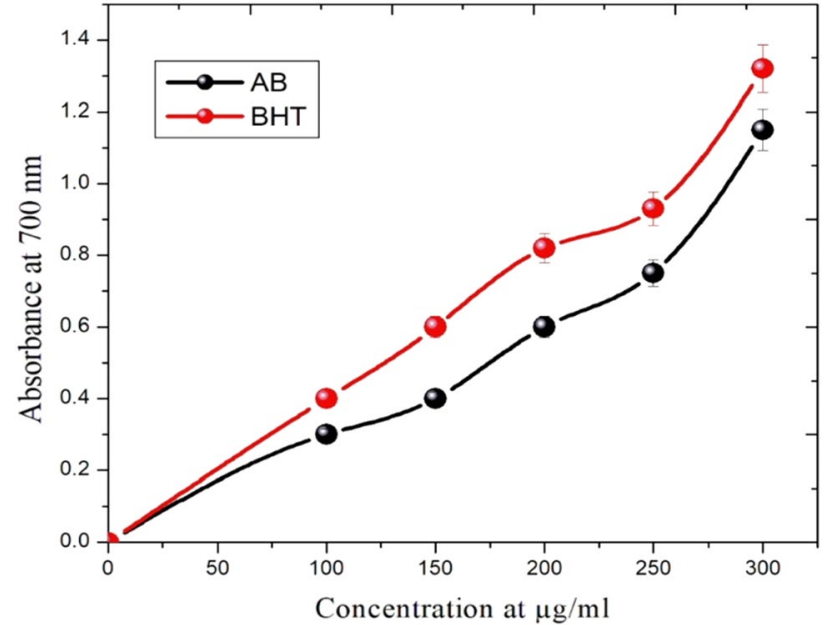

Fig. 5 Reducing power of A. bilimbi fruit extract compared with butylated hydroxytoluene (BHT). Each value is expressed as mean \pm standard deviation $(n=3)$

reactive oxygen species. In this study briefly expressed flavonoids (myricetin and luteolin) are prominent superoxide scavenger. The $\mathrm{IC}_{50}$ value of fruit extract and $\mathrm{BHT}$ were found to be 73 and $55 \mu \mathrm{g} / \mathrm{mL}$, respectively (Fig. 6). In the above results clearly demonstrated about fruit extract was found to be a notable reducing capability and scavenger of superoxide radicals generated by free radical system.

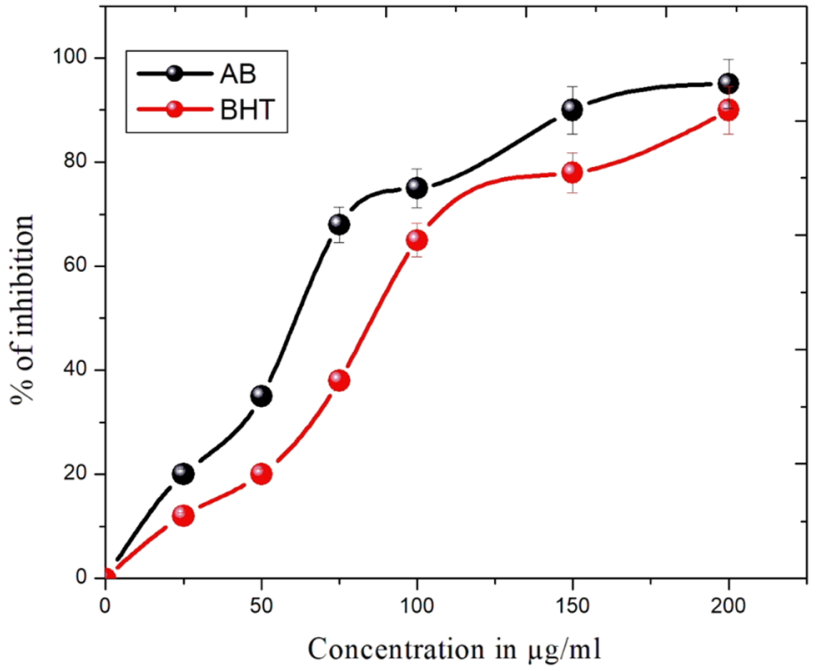

Fig. 6 Inhibitory effect of $A$. bilimbi fruit extract on superoxide anion radicals compared with butylated hydroxytoluene (BHT). Each value is expressed as mean \pm standard deviation $(n=3)$

The antimicrobial activity of present study carried out to identify minimum inhibitory concentration against E. coli, S. aureus and B. subtilis MIC was found 62.5, 80.3 and $80.5 \mu \mathrm{g} / \mathrm{mL}$ respectively (Table 1). A. Bilimbi leaves and fruit extract antimicrobial activity was previously reported by Zakaria et al. (Zakaria et al. 2007) by 
Table 1 Antimicrobial activity of A. bilimbi fruit extract

\begin{tabular}{llll}
\hline Bacteria species & $\begin{array}{l}\text { Total flavonoid content used } \\
(\mu \mathrm{g} / \mathrm{mL})\end{array}$ & Extract MIC $(\mu \mathrm{g} / \mathrm{mL})$ & $\begin{array}{l}\text { Streptomycin } \\
\text { MIC }(\mu \mathrm{g} / \mathrm{mL})\end{array}$ \\
\hline B. subtilis & $10-200$ & $25 \pm 5$ & $10 \pm 1$ \\
Staphylococcus aureus & $10-200$ & $50 \pm 3$ & $25 \pm 3$ \\
Escherichia coli & $10-200$ & $50 \pm 6$ & $25 \pm 2$ \\
\hline
\end{tabular}

$M I C$ minimum inhibitory concentration disc diffusion method, in this study carried out minimum inhibitory concentration through colorimetrically. A. Bilimbi fruit extract and root extract inhibits mycobacterium tuberculosis with minimum inhibitory concentration level of $1600 \mu \mathrm{g} / \mathrm{mL}$. further, hexane, methanol and chloroform extract of A. bilimbi bark antimicrobial activity shows positive results such as $S$. aureus, B. subtilis and E. coli and it reported as antifungal nature against Sacharomyces cerevacae, C. albicans and A. niger at $102.4 \mathrm{mg} / \mathrm{mL}$ (Rukayadi et al. 2013). The present study was demonstrated total flavonoid content versus antimicrobial activity was calculated for extract and commercial drug Streptomycin was used for reference analysis (Table 1). This study was clearly indicating that flavonoids content of $A$. bilimbi fruit extract play vital role against above pathogenic microbes.

\section{Conclusion}

The present study concludes A. bilimbi fruits flavonoids extraction was optimized and maximum yield (myricetin and luteolin) obtained in UCAE method with solid phase fraction, quantification was done using RP-HPLC method. Further, antioxidant capability of fruit was confirmed through superoxide radical scavenging activity and capability of reducing power of the extract. Antimicrobial activity was confirmed through minimum inhibitory concentration. The study proves method suitability of flavonoids extraction and quantification. The anti-microbial and antioxidant study clearly demonstrates free radical scavenging capability and antimicrobial activity was directly proportional to the total flavonoids content.

Acknowledgements Institute of Applied Science and Technology, Van Lang University, Ho Chi Minh, 700000, Vietnam for supporting this research. This project was supported by Researchers Supporting Project number (RSP-2021/230) King Saud University, Riyadh, Saudi Arabia.

\section{Declarations}

Conflict of interest The authors declare that they have no competing interests.

\section{References}

Adamczak A, Ożarowski M, Karpiński TM (2020) Antibacterial activity of some flavonoids and organic acids widely distributed in plants. J Clin Med 9(1):109

Albuquerque BR, Prieto M, Vázquez JA, Barreiro MF, Barros L, Ferreira IC (2018) Recovery of bioactive compounds from Arbutus unedo L. fruits: comparative optimization study of maceration/microwave/ultrasound extraction techniques. Food Res Int 109:455-471

Alhassan AM, Ahmed QU (2016) Averrhoa bilimbi Linn: a review of its ethnomedicinal uses, phytochemistry, and pharmacology. J Pharm Bioallied Sci 8(4):265

Alsarhan A, Sultana N, Kadir M, Aburjai T (2012) Ethnopharmacological survey of medicinal plants in Malaysia, the Kangkar Pulai region. Int J Pharmacol 8(8):679-686

Fu X-Q, Ma N, Sun W-P, Dang Y-Y (2018) Microwave and enzyme co-assisted aqueous two-phase extraction of polyphenol and lutein from marigold (Tagetes erecta L) flower. Indus Crops Prod 123:296-302

Goh SH, Chuah CH, Mok JSL, Soepadmo E (1995) Malaysian medicinal plants for the treatment of cardiovascular diseases. Pelanduk Publications

Gülçin I, Bursal E, Şehitoğlu MH, Bilsel M, Gören AC (2010) Polyphenol contents and antioxidant activity of lyophilized aqueous extract of propolis from Erzurum. Turkey Food Chem Toxicol 48(8-9):2227-2238

Gunawan, Cordero A, Paano A (2013) Structure elucidation of two new phytol derivatives, a new phenolic compound and other metabolites of Averrhoa bilimbi. DLSU Res Congress, pp 1-8

Hasanuzzaman M, Ali MR, Hossain M, Kuri S, Islam MS (2013) Evaluation of total phenolic content, free radical scavenging activity and phytochemical screening of different extracts of Averrhoa bilimbi (fruits). Int Curr Pharm J 2(4):92-96

Jayaprakasha GK, Patil BS (2007) In vitro evaluation of the antioxidant activities in fruit extracts from citron and blood orange. Food Chem 101(1):410-418

Jin EY, Lim S, Oh Kim S, Park Y-S, Jang JK, Chung M-S, Park H, Shim K-S, Choi YJ (2011) Optimization of various extraction methods for quercetin from onion skin using response surface methodology. Food Sci Biotechnol 20(6):1727-1733

Karabin M, Hudcova T, Jelinek L, Dostalek P (2015) Biotransformations and biological activities of hop flavonoids. Biotechnol Adv 33(6):1063-1090

Kaškonienė V, Maruška A, Kornyšova O, Charczun N, Ligor M, Buszewski B (2009) Quantitative and qualitative determination of phenolic compounds in honey. Cheminè Technologija 52(3):74-80

Miean KH, Mohamed S (2001) Flavonoid (myricetin, quercetin, kaempferol, luteolin, and apigenin) content of edible tropical plants. J Agric Food Chem 49(6):3106-3112

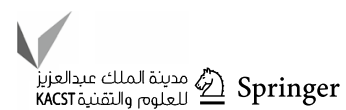


Patil AG, Koli SP, Patil DA (2013) Pharmcognostical standardization and HPTLC fingerprint of Averrhoa bilimbi (L.) fruits. J Pharm Res 6(1):145-150

Pino JA, Marbot R, Bello A (2004) Volatile components of Averrhoa bilimbi L. fruit grown in Cuba. J Essential Oil Res 16(3):241-242

Prasad NK, Yang B, Zhao M, Wang BS, Chen F, Jiang Y (2009) Effects of high-pressure treatment on the extraction yield, phenolic content and antioxidant activity of litchi (Litchi chinensis Sonn) fruit pericarp. Int J Food Sci Technol 44(5):960-966

Proestos C, Chorianopoulos N, Nychas G-J, Komaitis M (2005) RPHPLC analysis of the phenolic compounds of plant extracts. Investigation of their antioxidant capacity and antimicrobial activity. J Agric Food Chem 53(4):1190-1195

Rameshkumar A, Sivasudha T (2012) In vitro antioxidant and antibacterial activity of aqueous and methanolic extract of Mollugo nudicaulis Lam leaves. Asian Pacific J Trop Biomed 2(2):S895-S900

Rameshkumar A, Sivasudha T, Jeyadevi R, Sangeetha B, Ananth DA, Aseervatham GSB, Nagarajan N, Renganathan R, Kathiravan A (2013) In vitro antioxidant and antimicrobial activities of Merremia emarginata using thio glycolic acid-capped cadmium telluride quantum dots. Colloids Surf B 101:74-82

Rukayadi Y, Lau K, Zainin N, Zakaria M, Abas F (2013) Screening antimicrobial activity of tropical edible medicinal plant extracts against five standard microorganisms for natural food preservative. Int Food Res J 20(5):2905
Xie Z, Sun Y, Lam S, Zhao M, Liang Z, Yu X, Yang D, Xu X (2014) Extraction and isolation of flavonoid glycosides from Flos Sophorae Immaturus using ultrasonic-assisted extraction followed by high-speed countercurrent chromatography. J Sep Sci 37(8):957-965

Xu L, He W, Lu M, Yuan B, Zeng M, Tao G, Qin F, Chen J, Guan Y, He Z (2018) Enzyme-assisted ultrasonic-microwave synergistic extraction and UPLC-QTOF-MS analysis of flavonoids from Chinese water chestnut peels. Ind Crops Prod 117:179-186

Yen G, Chen H (1995) Antioxidant activity of different tea extracts in connection with their antimutagenicity. J Agr Food Chem 43:27-32

Zakaria Z, Zaiton H, Henie E, Jais A, Zainuddin E (2007) In vitro antibacterial activity of Averrhoa bilimbi L. leaves and fruits extracts. Int J Trop Med 2(3):96-100

Zhang QA, Fan XH, Li T, Zhang ZQ, Liu YK, Li XP (2013) Optimisation of ultrasound extraction for flavonoids from semen astragali complanati and its identification by HPLC-DAD-MS/MS. Int J Food Sci Technol 48(9):1970-1976

Publisher's Note Springer Nature remains neutral with regard to jurisdictional claims in published maps and institutional affiliations. 